\title{
POLÍTICAS PÚBLICAS PARA A MATERNIDADE: UMA ANÁLISE DAS LICENÇAS POR MATERNIDADE E PATERNIDADE À LUZ DA IGUALDADE E DA SUSTENTABILIDADE SOCIAL
}

\author{
Érika do Amaral Véras ${ }^{1}$ \\ Flavia de Paiva Medeiros de Oliveira²
}

\section{RESUMO:}

Este artigo aborda o tema do direito à maternidade e o seu exercício no ambiente de trabalho, sob o prisma do princípio da igualdade e à luz da sustentabilidade social com a finalidade de proporcionar às mulheres condições de igualdade com o homem para o ingresso e permanência no mercado de trabalho, bem como para garantir que as novas formas família possam exercer o direito à convivência com os filhos.

Palavras-chave: maternidade; políticas públicas; igualdade; sustentabilidade social; licenças

\section{PUBLIC POLICY FOR A MATERNITY: AN ANALYSIS OF THE MATERNITY AND FATHERHOOD LICENSE IN THE LIGHT OF EQUALITY AND SOCIAL SUSTAINABILITY}

\begin{abstract}
:
This article addresses the issue of the right to maternity and its exercise in the workplace, under the prism of the principle of equality and in the light of social sustainability, in order to provide women with conditions of equality with men for entering and remaining in the workplace. Labor market, as well as to ensure that the new family forms can exercise the right to live with their children.
\end{abstract}

Keywords: maternity; public policy; equality; social sustainability; licenses

\section{INTRODUÇÃO}

O direito à maternidade tem suma importância, principalmente quando se trata do seu exercício no ambiente de trabalho, uma vez que a gravidez e os cuidados com a prole contribuem para a discriminação feminina no mercado laboral. Tal razão é reforçada pelo pensamento tradicional e machista, baseado em preconceitos e estereótipos, de que a função da mulher na sociedade é meramente reprodutiva. A mulher era vista como a única responsável pelo mundo familiar, o ambiente privado, diferentemente do homem que era o

\footnotetext{
${ }^{1}$ Mestranda em Direito e Desenvolvimento Sustentável do UNIPÊ; Especialista em Ordem jurídica, Ministério Público e Cidadania pela Fundação Escola Superior do Ministério Público do Estado da Paraíba - FESMIP; Advogada; Empregada Pública.

${ }^{2}$ Doutora em Direito do Trabalho e Previdência Social pela Universitat de València; Mestre em Direito pela Universidade Federal do Ceará; Professora do Programa de Pós-Graduação em Direito e Desenvolvimento do Centro Universitário de João Pessoa - UNIPÊ; Advogada.
} 
responsável pelo ambiente público, o mundo produtivo. Imaginar a possibilidade da mulher ingressar nesse universo masculino foi praticamente impossível durante um largo período de tempo.

É notório que a maternidade, consequentemente o cuidado com os filhos, foi (e continua sendo) uma das principais razões para o impedimento da inserção feminina no mercado de trabalho, ou, se inserida, limita a realização do trabalho, diante da necessidade de conciliação entre o trabalho e a família.

A escolha entre a vida familiar e profissional impossibilita a maior dedicação da mulher à carreira, tendo desvantagens em relação aos homens, que, em geral, podem se dedicar exclusivamente à vida profissional, uma vez que os afazeres domésticos e os cuidados com os filhos ficam, normalmente, sob a responsabilidade da mulher.

Em razão da cada vez crescente da inserção feminina no trabalho fora do lar, principalmente durante a industrialização, foram surgindo diversas normas protetivas relacionadas ao trabalho da mulher, visando criar condições de igualdade e competitividade para com os homens.

Vale frisar que a proteção à maternidade não se restringe apenas ao direito de procriação, ele está diretamente relacionado à garantia da saúde, tanto da gestante quanto de seu filho, e dos cuidados necessários à manutenção da gestação, acompanhando também os primeiros meses de vida da criança, afastando todos os riscos à vida de ambos.

Com o objetivo de amenizar a exclusão da mulher nesta seara, criou-se o instituto da licença maternidade como forma de proteção ao mercado de trabalho feminino, no que se refere ao acesso, bem como à sua manutenção e garantia de igualdade. Foi a partir de então que a mulher encontrou um meio possível de se dedicar à carreira profissional sem interferir na vida pessoal.

Este trabalho objetiva, portanto, conceder ao leitor uma visão geral sobre a temática da proteção à maternidade no ambiente de trabalho, de forma a verificar seus aspectos fundamentadores, assim como avaliar se a licença maternidade serve apenas para proteger a mulher no pós-parto, evitando a discriminação, ou se opera o condão de incluí-la laboralmente. Para tanto, em um primeiro momento, à proteção à maternidade será analisada sob o ângulo das políticas públicas e da sustentabilidade social como instrumento concretizador do princípio constitucional da igualdade. 
Em seguida o assunto será abordado sob o prisma normativo, demonstrando a importância de proporcionar às mulheres, especialmente as gestantes, condições de igualdade para o ingresso e permanência no mercado de trabalho, através de normas protetivas. Por fim, faremos um estudo sobre a licença paternidade e a licença parental, a fim de demonstrar que a efetiva inserção social e laboral da mulher requer a implantação de uma nova fórmula jurídica, qual seja, a licença parental.

Para tanto, o método de abordagem escolhido para a elaboração do presente artigo foi o método indutivo, discorrendo sobre a mulher e o direito à maternidade no ambiente de trabalho. Para o método de procedimento foi selecionado o método histórico que proporcionou melhor entendimento sobre as transformações sofridas pela sociedade, bem como pelas legislações reguladoras sobre o assunto em questão. E, por fim, a técnica de pesquisa aplicada para coleta de dados foi basicamente a bibliográfica.

\section{A NECESSIDAde de POLÍticas PÚBliCAS PARA A MATERNIDAdE: UMA QUESTÃO DE IGUALDADE E DE SUSTENTABILIDADE SOCIAL}

A discriminação a que a mulher foi submetida ao longo da evolução do ser humano é histórica e decorre, em grande parte, do papel que lhe foi atribuído dentro do lar, correspondendo-lhe nesse âmbito as tarefas de cuidar da casa e dos filhos. Essas tarefas eram consideradas as mais fáceis e, portanto, as mais aptas à condição de fragilidade de que a supostamente gozava. O homem foi encarregado de enfrentar as situações mais difíceis do cotidiano, tais como, caçar, pescar e defender o território. Como consequência dessa divisão de papéis que remonta aos primórdios da humanidade, legou-se à mulher uma suposta condição de fragilidade para a prática de certas atividades, ao mesmo tempo em que se lhe atribuía um encargo considerado primordial para a existência da vida, qual seja, o de ser mãe.

Não obstante, malgrado a maternidade seja um atributo exclusivo da mulher, mister se faz que os instrumentos normativos concebidos pelo ordenamento jurídico para garantir o exercício desse direito sejam analisados para permitir sua inclusão no mercado de trabalho, ao invés de servir para excluí-la da vida profissional, privando-a do exercício de um direito humano fundamental, que é o direito ao trabalho. 
Para que haja uma compatibilização entre o direito à maternidade e o direito ao trabalho, impende que haja políticas públicas voltadas para fomentar o respeito a esse direito e, sobretudo, que ele seja encarado por um prisma de sustentabilidade social.

As políticas públicas se caracterizam por serem diretrizes e princípios norteadores da ação do poder público, transformando-se em regras ou procedimentos capazes de estabelecer um diálogo entre o poder público e a sociedade. Representam, portanto, uma das formas de interação e de diálogo entre o Estado e a sociedade civil, por meio da transformação de diretrizes e princípios norteadores em ações, regras e procedimentos que (re)constroem a realidade. Sua co-relação com a perspectiva de gênero é recente e, no Brasil, remontam à década de 1970 (BANDEIRA; ALMEIDA, 2004). É necessário compreender que as políticas públicas com recorte de gênero têm como ponto de partida a diferença existente entre os gêneros e, com base nesse reconhecimento, implementam ações diferenciadas dirigidas às mulheres com vistas a emancipá-las e conferir-lhes autonomia (FARAH, 2004).

As garantias conferidas à mulher e que lhe asseguram o exercício do direito de ser mãe precisam ser analisadas como integrante de um conjunto de políticas públicas cuja finalidade é inserir socialmente a mulher em condições de igualdade com o homem. Entender de forma diversa tais prerrogativas legais, analisando-as isoladamente, ao invés de vislumbrálas como uma forma de inserir a mulher mãe no mercado de trabalho, servirá para agravar a situação discriminatória que se quer corrigir e não, como se pretende, para mitiga-la.

Nesse contexto, é importante entender o direito à maternidade e as prerrogativas legais estabelecidas para permitir o exercício desse direito, bem como as políticas públicas que versam sobre questões de gênero pelo prisma da sustentabilidade social e à luz do disposto no art. $1^{\circ}$, III e no art. 170, da Constituição de 1988 (CF/1988). O primeiro prevê que a dignidade humana é um dos princípios fundamentais do Estado Democrático de Direito brasileiro. O segundo dispositivo constitucional dispõe que a ordem econômica tem como alicerce a valorização do trabalho humano realizado para viabilizar uma existência digna. Com base em tais dispositivos constitucionais, dessume-se que o direito de ser mãe não exclui o direito ao trabalho, bem como este não pode inviabilizar o exercício daquele.

Sob a perspectiva social, a sustentabilidade consiste no modo de convívio social no qual a liberdade, a segurança, o bem-estar, o desenvolvimento, a igualdade, e a justiça constituem os valores capazes de efetivar uma sociedade solidária e participativa, preocupada e atenta para o bem-estar, não só das presentes, mas das futuras gerações (COELHO; 
ARAUJO, s/d). Assim sendo, entender o direito à maternidade e as garantias que viabilizam o seu exercício, sobretudo, a licença à maternidade, como uma decorrência da sustentabilidade social e como parte integrante de um programa de políticas públicas permite pensar nesses direitos e ações como mecanismos destinados não só a mitigar a discriminação feminina, mas como um vetor de promoção da igualdade para as gerações existentes e por vir por meio do qual se inclui a mulher no mercado de trabalho em condições de igualdade com o homem. É sob esse ângulo que o direito à licença maternidade deve ser visto, já que constitui o núcleo legal básico da proteção à maternidade.

Quando se vislumbra a licença maternidade pelo prisma da sustentabilidade social, o que se quer viabilizar é que essa licença, que assume natureza jurídica de direito fundamental da mulher trabalhadora, não seja encarada apenas como forma de proteg e-la no seu pósparto. Ao contrário, o que se pretende é que tal licença seja vista como um instrumento garantidor de inserção laboral da mãe trabalhadora.

Para isso, mister propugnar pela inserção de um novo instituto na ordem jurídica pátria que, ademais de contemplar a saúde da mulher no pós-parto, atendendo às suas particularidades biológicas, seja capaz de permitir uma distribuição igualitária das responsabilidades familiares entre o homem e a mulher, com vistas a criar um ambiente jurídico favorável à superação do paradigma patriarcal sobre o qual se erigiu o modelo constitucional que previu prazos de licença diferenciados para o homem e a mulher que assumem o encargo de criação dos filhos. A diferenciação desses prazos destaca uma maior responsabilidade da mulher no que atine à criação dos filhos, o que dificulta a sua inserção e reinserção no mercado de trabalho após a maternidade.

Assim sendo, a sustentabilidade social, visualizada como um modo de convívio social, que deve ser norteado pelo valor igualdade, faz nascer a necessidade social de criação de novos institutos jurídicos, que sejam capazes de trazer para o ambiente de trabalho a igualdade existente no seio da família e prevista no art. 226, da Carta Magna, segundo o qual se compartilham igualitariamente os encargos materiais e morais da criação e educação dos filhos.

\section{DIREITO À MATERNIDADE NO TRABALHO}


A participação cada vez maior da mulher no emprego assalariado, passando a fazer parte da população economicamente ativa, é uma constante, principalmente a partir da década de 70. Nem mesmo as crises econômicas enfrentadas por nosso país foram capazes de frear esse processo de absorção da mão de obra feminina.

O trabalho feminino passou a significar mão de obra barata e, até mesmo, trabalho informal. O drama vivido pelas mulheres dentro das fábricas, em que as condições de trabalho eram marcadas pela ínfima segurança e a ausência de um ambiente de trabalho saudável, sensibilizou a opinião pública da época e, desde então, as normas protetoras do trabalho subordinado e remunerado passaram a adotar como objeto o trabalho feminino.

Verifica-se que as diversas normas, nacionais e internacionais, relacionadas ao trabalho da mulher, possuíam um caráter extremamente protetivo. Segundo Nascimento (1996, p. 18) a fase protetora do trabalho feminino foi marcado pela elaboração de Convenções e Recomendações sobre maternidade, trabalho noturno, insalubre, perigoso, duração da jornada de trabalho, trabalhos manuais e que envolvem cargas, segurança e higiene no trabalho, dentre outros. Essas regras são destinadas a preservar a reprodução da espécie humana, assegurando as condições para que a mulher pudesse cumprir concomitantemente com o trabalho as obrigações familiares.

Porém, esse excesso de protecionismo por parte do Estado com relação ao trabalho feminino resultou em enormes barreiras ao ingresso da mulher no mercado de trabalho. Tais normas foram criticadas por desrespeitar o princípio da igualdade, restringir o mercado de trabalho da mulher, reforçando a divisão sexista das atividades laborais. Dessa forma, visando reverter esse quadro, houve uma lenta e progressiva flexibilização das normas passou a ocorrer, objetivando alcançar a igualdade de oportunidades e tratamento entre trabalhadores e trabalhadoras (VIEGAS E SILVA, 2016).

\subsection{AS NORMAS DA ORGANIZAÇÃO INTERNACIONAL DO TRABALHO (OIT) QUE TRATAM DA MATERNIDADE}

A OIT, em suas primeiras convenções, voltadas ao trabalho da mulher, destacou sua preocupação com a proteção contra as condições penosas de trabalho, sobretudo, no que concerne à integridade física da mulher, especialmente quando se encontrar durante o período de gestação. Tal assunto era de tamanha importância para OIT, que em sua primeira 
Conferência Internacional do Trabalho, em 29 de outubro de 1919, intitulada de Convenção relativa ao Emprego das Mulheres antes e depois do parto (Proteção à Maternidade), demonstrou ser essa temática uma das principais preocupações dos Estados-membros da OIT, desde a sua criação. Conhecida como Convenção nº 03 (OIT, 1919) ${ }^{3}$.

Mais adiante, a OIT elaborou a Convenção $n^{\circ} 103$ (OIT, 1952) ${ }^{4}$, tratando sobre o amparo à maternidade, aplicando-se às mulheres ${ }^{5}$ empregadas em empresas industriais (públicas ou privadas) bem como às mulheres empregadas em trabalhos não industriais (serviço público ou privado) e agrícolas, inclusive às mulheres assalariadas que trabalham em domicílio. Tal convenção prevê o direito de toda mulher, mediante comprovação por atestado médico, a uma licença maternidade, com duração mínima de doze semanas, onde uma parte dessa licença (no mínimo de seis semanas) deverá ser gozada, obrigatoriamente, após o parto, recebendo prestações em espécie e a assistência médica necessária. Ainda prevê uma licença pré-natal suplementar nos casos de doença confirmada por atestado médico como resultante da gravidez. Autoriza, ainda, a mulher, no período de amamentação, a interromper seu trabalho para que a mesma amamente seu filho, durante um ou vários momentos. Também prevê a estabilidade da gestante trabalhadora ao proibir o empregador de despedi-la durante a vigência do benefício da licença maternidade, vez que considerou esta prática como ilegal.

A não concessão aos homens de um instrumento equivalente à licença maternidade, em nossa ordem jurídica, funciona muitas vezes como uma autorização implícita para que eles se dediquem a outros objetivos e se esquivem de uma participação mais direta e de uma divisão mais igualitária do ônus decorrente do dever de cuidado com os filhos e da casa.

Por meio da Convenção no 156 (OIT, 1981), a OIT destacou a necessidade de haver uma igualdade de responsabilidades familiares entre homens e mulheres que trabalham e, no seu art. $1^{\circ}$, dispôs que: "Esta convenção aplica-se a homens e mulheres com responsabilidades com relação a seus filhos dependentes, quando estas responsabilidades restringem a possibilidade de se prepararem para uma atividade econômica e nela ingressar, participar ou progredir”. A finalidade da norma internacional é estabelecer uma efetiva igualdade de oportunidade e de tratamento para homens e mulheres trabalhadores, pelo que previu que cada Estado-membro devia adotar medidas para permitir que pessoas com responsabilidades

\footnotetext{
${ }^{3}$ Ratificada através do Decreto n ${ }^{\circ} 423 / 35$.

${ }^{4}$ Ratificada através do Decreto no $58.820 / 1966$.

${ }^{5}$ Segundo a referida convenção, "o termo mulher designa toda pessoa do sexo feminino, qualquer que seja sua idade ou nacionalidade, raça ou crenças religiosas, casada ou não".
} 
familiares exerçam seu direito de assumir um emprego sem serem discriminadas, compatibilizando-o com suas responsabilidades familiares.

De igual modo, prevê que os Estados devem implementar medidas para permitir às pessoas a livre escolha de ocupações, o acesso à educação e a reintegração à força de trabalho após uma ausência em função de responsabilidades familiares. Contempla, ainda, a adoção de medidas com relação ao desenvolvimento de serviços comunitários, públicos e privados de assistência à infância e à família que levem em conta as necessidades desse grupo de trabalhadores e trabalhadoras. Por último, assinala claramente que as responsabilidades familiares não devem constituir, por si só, uma causa para demissão. Entretanto, o Brasil não ratificou a referida convenção.

Para complementar esta convenção, foi elaborada a Recomendação nº 165 (OIT, 1981), que prevê uma igualdade de direitos e obrigações com relação aos encargos familiares, estabelecendo que, tanto homens como mulheres, são responsáveis por seus filhos e, por essa razão, ambos devem ter direito a uma licença parental em um período posterior à licença maternidade, sem perder o seu emprego, conservando os direitos que dele derivam. Dispõe também que homens e mulheres deveriam ter direito a obter uma licença para se ausentar do trabalho em caso de enfermidade de seu filho ou filha ou de outro membro da sua família. A instituição de tais licenças e, especialmente da licença parental, possui uma grande importância no sentido da redução das desigualdades advindas dos encargos de família, conduzindo para igualdade de gênero.

Da avaliação das normas da OIT acima tratadas, inferimos que a citada organização reconhece que a proteção à maternidade não depende apenas da concessão de direitos à mãe no seu pós-parto. As normas internacionais analisadas revelam que é imperioso que se garanta à mulher uma igualdade de oportunidades, o que passa necessariamente pela redefinição dos encargos familiares, através do qual se tenta criar dentro do lar um cenário de compartilhamento dos ônus materiais e psíquicos com a família de forma igualitária entre os pais, a fim de que essa almejada igualdade dentro do lar com relação à família alcance também a sociedade e, por consequência, as unidades empresariais.

Esse é o pilar que deve servir como critério de interpretação para as normas internas, que versam sobre a proteção ao trabalho da mulher e, em especial, sobre a maternidade, assim como deve nortear a condução das políticas públicas nacionais. 


\subsection{A CONSTITUIÇÃO FEDERAL DE 1988}

Após a derrocada do regime militar, nosso país passou por mudanças políticas. Alguns movimentos, preocupados com o trabalho da mulher, influenciaram a elaboração da nova Carta Magna, ao revelar a discriminação, a precária condição do trabalho, as dificuldades da maternidade em face do emprego, dentre outras questões.

A CF/1988 passou a instituir direitos e garantias fundamentais, destacando o princípio da igualdade (art. $5^{\circ}$, caput, I). Vale frisar que o princípio da igualdade não se restringe ao tratamento absolutamente igual a todos, mas permite o tratamento desigual diante das desigualdades. Neste sentido, Calil (2007, p. 50) afirma que a Constituição “[...] privilegiou a isonomia entre homens e mulheres, apenas diferenciando onde a desigualdade se faz patente, como é o caso, v.g, da maternidade”. Visando promover tal proteção, a Constituição Federal afirmou expressamente a proteção à maternidade (art. $6^{\circ}$, caput), assegurando à gestante licença (art. $7^{\circ}$, XVII) de 120 (cento e vinte dias), sem prejuízo do emprego e do salário, bem como, é possível encontrar no art. 10, II, "b", do Ato das Disposições Constitucionais Transitórias - ADCT, a garantia do emprego da gestante desde a confirmação da gravidez até cinco meses após o parto. Apesar dessas grandes conquistas de direitos por parte das mulheres, ainda é muito frequente a discriminação no mercado de trabalho, sobretudo, com preterição nas vagas de emprego e percepção de salários menores do que aqueles pagos aos homens para o exercício da mesma função, sendo a gravidez um dos principais fatores para esse tratamento discriminatório.

Dessa forma, podemos considerar que o exercício do direito de ser mãe, malgrado possua uma importante função social de renovação das gerações, pode ser encarado como um fator capaz de agravar a real desigualdade entre os gêneros, já que a condição de ser mãe afeta as perspectivas de inserção laboral do coletivo feminino no mercado de trabalho por não haver uma separação entre os papéis que ela ocupa na esfera pública, entendida como tal a sociedade, e o que ela desempenha no âmbito privado, o lar (VIEGAS E SILVA, 2016, p. 12).

É por esse motivo que as normas protetivas trabalhistas destinadas à garantir o direito à maternidade devem ser entendidas à luz de uma conjuntura de políticas públicas e sob o prisma da sustentabilidade social, visto que a sua finalidade não consiste apenas em viabilizar o exercício do direito de ser mãe, mas de permitir que ele seja exercido em uma sociedade que 
propugna pela inserção social e laboral do coletivo feminino em condições de igualdade com o masculino, o que acarreta o respeito à maternidade como fator, social e biológico, de renovação.

\section{PROTEÇÃO À GESTANTE}

Importante se faz refletir sobre as principais questões jurídicas que envolvem a temática da tutela trabalhista para as mulheres, especialmente às gestantes. Neste momento, passaremos a analisar, de forma minuciosa, a licença maternidade, que constitui a principal política pública de proteção à maternidade. Tal licença se configura como uma política pública, porque o ordenamento jurídico pátrio lhe atribuí a feição jurídica de benefício previdenciário, já que, ainda que o empregador arque diretamente com o pagamento desse benefício, poderá proceder à compensação do valor pago à empregada mãe com encargos previdenciários que devem ser recolhidos ao Instituto Nacional de Previdência Social (INSS).

Essa medida protetiva é importante diante da necessidade de proteção à gestante, uma vez que a gravidez e os primeiros meses após o parto formam um período de maior vulnerabilidade da mulher em que esta se encontra exposta a uma série riscos potenciais à saúde. Trabalhar durante esse período não representa um risco em si, por não ser a gravidez uma doença. No entanto, durante a gestação, no parto e no período pós-parto, há riscos particulares para a saúde da mulher e do seu filho, que podem implicar a necessidade de uma proteção especial (VIEGAS E SILVA, 2016, p. 2).

A licença maternidade corresponde ao período no qual a gestante ou mãe adotiva permanecem afastadas das suas funções laborais sem prejuízo da remuneração e do emprego, percebendo o benefício previdenciário correspondente ao salário maternidade. Este período de afastamento concedido à trabalhadora gestante é norma imperativa, não podendo ser objeto de negociação ou renúncia por parte da empregada, nem mesmo através de acordo coletivo. Nesse sentido, Barros (2009, p. 1087) assevera que as normas de proteção à maternidade são cogentes e não podem ser afastadas, nem mesmo com o consentimento da gestante, sob pena de imputação de penalidade administrativa ao empregador, prevista no art. 401, da CLT.

Durante largo período, em nosso País, era adotado um critério de proteção da empregada gestante incompatível com a nossa realidade. Cabia ao empregador o encargo da remuneração da empregada durante as 12 semanas de afastamento do serviço, devido à 
gravidez. Como se tratava de um encargo financeiro com o qual o empregador devia arcar, a admissão de mulheres casadas ou com filhos passou a ser negada de forma velada, o que gerava discriminação (HORVATH JÚNIOR, 2016).

Esse quadro passou a mudar consideravelmente com o advento da Lei nº 6.136, de 07 de novembro de 1974, que tornou a Previdência Social o órgão responsável pela remuneração da gestante durante o seu afastamento do serviço. A partir desse marco legal, o salário maternidade passou a ter natureza jurídica de benefício previdenciário. E, desde então, a presença da mulher (e mãe) cresceu no mercado de trabalho.

Com a CF/1988, a licença maternidade teve o prazo estendido de noventa para cento e vinte dias, bem como regulou a estabilidade e garantia do emprego da gestante desde a confirmação da gravidez até cinco meses após o parto, ficando proibida a dispensa arbitrária ou sem justa causa. Diante desta proteção, Mandalozzo (1996, p. 144) afirma que o “fundamento da licença-maternidade é o princípio da continuidade da relação empregatícia".

Também devemos destacar a Lei $\mathrm{n}^{\circ} 11.770$, de 09 de setembro de 2008, que criou o Programa Empresa Cidadã, destinado à prorrogação da licença maternidade mediante a concessão de incentivo fiscal. A referida lei autoriza às mães trabalhadoras requerer, até o final do primeiro mês após o parto, a prorrogação da licença maternidade por mais sessenta dias, que será concedida imediatamente após a fruição da licença maternidade. Esta prorrogação também é garantida, na mesma proporção, à mãe biológica e àquela que adotar ou obtiver guarda judicial para fins de adoção de criança. O referido benefício só será aplicado aos funcionários das empresas que, voluntariamente, optarem pelo Programa Empresa Cidadã e forem tributadas com base no lucro real. Consequentemente, estas empresas poderão deduzir do imposto devido, em cada período de apuração, o total da remuneração paga durante os dois meses de prorrogação da licença, sendo vedado a dedução como despesa operacional.

Ressalta-se que todas essas proteções destinadas à maternidade também se estende à mãe adotiva, em razão da Lei $\mathrm{n}^{\mathrm{o}}$ 10.421/2002, que lhe concedeu o direito à licença maternidade e ao salário maternidade. Por meio da Lei $\mathrm{n}^{\mathrm{o}} 12.873 / 2013$, a empregada que adotar ou obtiver a guarda de criança para adoção futura também tem direito a licença maternidade de cento e vinte dias, pagos pela Previdência Social, bem como a contagem do tempo de serviço, independentemente da idade da criança. Essa última Lei equiparou o prazo 
da licença maternidade nos casos de adoção ou guarda, que, anteriormente, era exercido de forma proporcional à idade da criança a ser adotada.

Este direito é de extrema importância uma vez que a mulher trabalhadora, ao adotar, está cumprindo o seu papel social passando a ter todos os deveres, obrigações e responsabilidades inerentes à filiação, tal como ocorre com a gestante, devendo, assim, gozar dos mesmos direitos quando do seu afastamento laboral, utilizando-se do gozo integral da licença maternidade.

O legislador também preservou o direito das mulheres que sofrem aborto espontâneo de gozarem de um repouso remunerado de duas semanas a título de salário maternidade (art. 93, $\S 5^{\circ}$, do Decreto n. 3.048/99 c/c art. 395 da CLT), sendo-lhe assegurado o retorno à função ocupada anteriormente ao afastamento. Ocorrendo parto antecipado, ainda que de natimorto, comprovado por atestado médico, a empregada terá direito a cento e vinte dias de salário maternidade (art. 93, $\S 4^{\circ}$, do Decreto n. 3.048/99) e à estabilidade prevista no artigo 10, II, b, do ADCT.

Vale frisar que a proteção dispensada pela lei à empregada grávida não é condicionada ao prévio conhecimento desse fato pela empresa, conforme entendimento sedimentado na Súmula 244, do Tribunal Superior do Trabalho (TST). Em caso de dispensa arbitrária da gestante, tem ela direito aos salários correspondentes ao período compreendido entre o momento da dispensa e o término da estabilidade provisória, ou seja, os cinco meses após-parto. É claro que deve a empregada comunicar ao empregador seu estado gravídico, mas, se não o fizer, nem por isso perde o direito às vantagens especiais que a lei lhe assegura. Da mesma forma, é facultado à mulher tomar a iniciativa de extinguir o contrato de trabalho, desde que o cumprimento deste seja prejudicial à gestação, comprovado por meio de atestado médico (art. 394, da CLT). Neste caso, a exigência de aviso prévio desaparece diante da necessidade de maior relevância de proteger a saúde da mulher e do filho.

Toda essa proteção destinada á gestante ratifica o pensamento de Melo (2011, p.37) ao afirmar que as condições gestacional e parturiente, seguido da amamentação, são fatores de discrímen suficientes para que a mulher seja destinatária de uma licença específica, servindo para que a mesma consiga perpassar por estes momentos, do que decorre, portanto, que a finalidade da proteção legal consiste em evitar a discriminação da mulher no período pósparto e não de garantir a sua inserção no mercado de trabalho. 


\section{A LICENÇA PATERNIDADE: DIFERENCIAÇÃO INJUSTIFICADA}

A CF/1988, no art. $10, \S 1^{\circ}$, do ADCT, previu a licença paternidade com um período mínimo de cinco dias. Diferentemente da licença maternidade, este benefício possui natureza salarial, pois é custeado pelo empregador, constituindo hipótese de interrupção do contrato de trabalho.

A duração reduzida dessa licença e o fato de estar a encargo do empregador refletem, do ponto de vista legal, uma postura machista e discriminatória com relação à concepção desse tipo de licença, revelando que se confere à mãe, quase que exclusivamente, o encargo com os cuidados dos filhos. Nesse sentido, Teixeira (2010, p. 259) assevera que:

$\mathrm{O}$ tratamento diferenciado dado à mulher em matéria de licença-maternidade, em contraste com a licença-paternidade, que têm ocasião em decorrência do mesmo evento, a reprodução, reforça e institucionaliza a discriminação de papéis sociais tradicionalmente conferidos a homens e mulheres.

Aos poucos, esse pensamento está sendo afastado, a exemplo da recente Lei $\mathrm{n}^{\circ}$ 13.257, de 08 de março de 2016, que alterou o inciso II do artigo 473 da Consolidação das Leis do Trabalho - CLT, estipulando o aumento da licença paternidade de cinco para vinte dias. Para ter direito ao período ampliado, a empresa em que o pai trabalha precisa estar vinculada ao Programa Empresa Cidadã. Se a empresa não fizer parte do programa, o pai tem direito a cinco dias apenas.

De acordo com a nova regra, a prorrogação da licença paternidade será concedida ao trabalhador que pedir o benefício no prazo de dois dias úteis após o nascimento do filho. Tal benefício também foi estendido ao empregado que adotar ou obtiver guarda judicial para fins de adoção de criança. Todavia, durante o período da licença paternidade, o pai não pode exercer nenhum trabalho remunerado, sob pena de perda do direito.

Isto posto, não há qualquer diferenciação entre sexos acerca do dever moral de cuidado e de proteção da prole na Constituição Federal de 1988. Pelo contrário, o texto constitucional "realça esse dever atribuído ora à 'família', ora aos 'pais' como obrigação jurídica igualitariamente direcionada a homens e mulheres”, sendo as licenças estudadas o instrumento jurídico capaz de viabilizar o cumprimento desses deveres. (TEIXEIRA, 2010, p. 265).

A devida regulamentação da licença paternidade torna-se imprescindível em razão da necessidade de apoio à mãe após o nascimento do filho ou da chegada da criança adotada ao 
lar e do estreitamento e adaptação dos pais com a criança nos dois casos, além da proteção da infância e da família.

Diante deste quadro, torna-se cristalino que a ausência da regulamentação dessa licença afasta a possibilidade e o estímulo a uma maior responsabilização do pai pelos encargos familiares. Consequentemente, reforça a discriminação contra a mulher e a manutenção da sociedade patriarcal, do mesmo modo que, ainda, discrimina os homens ao impedi-los de ter o mesmo contato e estabelecimento de vínculo com os filhos.

Mister, ainda, destacar que o fato de a licença conferida ao pai ser consideravelmente menor do que a dispensada à mãe, viola disposição contida no art. 226, da CF/1988, que reparte igualitariamente os ônus quanto à criação dos filhos entre os pais, sem qualquer distinção com relação ao sexo. Disso dessumimos que essa igualdade preconizada no artigo citado fica restrita ao âmbito familiar e não alcança a sociedade na qual incluem as empresas nas quais as mães trabalham.

\section{LICENÇA PARENTAL: UMA QUESTÃO DE IGUALDADE E DE SUSTENTABILIDADE SOCIAL}

A fórmula de proteção à maternidade adotada pelo direito brasileiro, fundamentada na dualidade da licença maternidade e da licença paternidade, não atende à necessidade de inserção laboral da mulher em condições de igualdade com o homem, pelo que podemos afirmar que se torna insustentável do ponto de vista social, violando o princípio constitucional da igualdade, como também o prescrito no art. 226, da $\mathrm{CF} / 1988$, que prevê que as responsabilidades familiares devem ser compartilhadas igualitariamente entre o homem e a mulher.

Por uma parte, na medida em que se estabelece um lapso temporal menor de licença paternidade, fica claro que as responsabilidades com a criança recaem em maior escala sobre a mãe. Por outro ângulo, mister vislumbrar que essa fórmula jurídica também não é consentânea com a realidade social atual, na qual a possibilidade de constituição de família contempla como uma de suas formas a união homoafetiva. 
Nesse caso concreto, em sendo a união homoafetiva constituída por duas pessoas do sexo feminino, mister perquirir se as duas terão direito à concessão da licença maternidade ${ }^{6}$. $\mathrm{Na}$ hipótese em que tal união seja formada por duas pessoas do sexo masculino, o direito dos pais será limitado apenas à licença paternidade cujo prazo é bem menor do que o concedido à mãe.

Nessas situações específicas acima enumeradas, tem-se uma nítida violação do princípio da igualdade, pelo que se impõe uma reavaliação dessa dualidade de licenças concebidas pelo ordenamento jurídico interno.

O mais apropriado para garantir a inserção laboral da mulher, que pretende ser mãe, em condições de igualdade com o homem, bem como de solucionar os questionamentos feitos anteriormente, é adoção da licença parental, que se configura como uma licença a longo prazo, colocada à disposição de um ou de ambos os pais, que lhes permite vivenciar a criação dos filhos, durante um período de tempo que pode, inclusive, ser posterior à própria licença maternidade ou paternidade (VIEGAS E SILVA, 2016, p. 6).

Segundo Barros (1995, p. 91) a licença parental aparece como consequência da transição entre o conceito de "pátrio poder" e o de "autoridade parental" cuja finalidade é tornar o pai cada vez mais participante das responsabilidades familiares e, por conseguinte, impedir que os cuidados com a educação e criação dos filhos recaiam exclusivamente sobre a mãe.

A licença parental é fundamental para a modificação dos padrões comportamentais de homens e mulheres com relação à distribuição do trabalho produtivo e reprodutivo, destacando a importância do exercício da paternidade e o papel do pai no nascimento dos filhos. Torna-se nítido que para alcançar a plena igualdade entre homens e mulheres, é necessário modificar o papel tradicional de cada um na sociedade e na família. Infelizmente, nosso país ainda não reconhece a licença parental.

Convém destacar que, nos países em que tal instituto foi adotado, o exercício do direito à referida licença nem sempre garante o pagamento integral da remuneração percebida pelo pai ou mãe, que a utiliza. Na Suécia, por exemplo, são disponibilizados aos pais 480 (quatrocentos e oitenta dias) de licença parental. Cada um dos pais é obrigado a gozar de pelo

\footnotetext{
${ }^{6}$ Vid. decisão prolatada nos autos do Processo ${ }^{\circ}$ 1002983-75.2016.8.26.0201 (Mandado de Segurança), no âmbito do TJSP, em que foi reconhecido o direito à licença maternidade apenas à mãe biológica, tendo a juíza sentenciante entendido que a concessão do direito às mães afeta o princípio da igualdade com relação à casais heterossexuais, já que os mesmos não são titulares do direito de gozarem de duas licenças maternidades (Disponível em: http://www.migalhas.com.br/arquivos/2016/10/art20161021-11.pdf. Acesso em: 09 maio 2017).
} 
menos 60 (sessenta), ficando o resto do tempo a ser decidido pelo casal sobre quem desfrutará do benefício, podendo ser gozado até que a criança complete 08 (oito) anos. O direito suíço também prevê a possibilidade de o pai ou mãe reduzir a sua jornada de trabalho em até 8 (oito) horas semanais, até que a criança complete a idade mencionada, o que se apresenta como uma importante medida para compatibilizar a vida familiar e laboral (MEULDERS ET AL, 2007).

Guardadas as devidas proporções sociais, culturais e econômicas que separam a realidade brasileira da suíça, há que se atentar para o fato de que o caminho juridicamente posto em prática naquele país europeu, é mais consentâneo com a necessidade de garantir uma inserção igualitária de homens e mulheres no mercado de trabalho, posto que divide as responsabilidades familiares, na medida em que reparte os ônus entre os pais, permitindo-lhes a possibilidade de um igual exercício da licença parental para criação dos filhos.

Além do que esse instituto jurídico, permite que a paternidade ou maternidade exercidas por pais ou mães que vivem em uma união homoafetiva, recebamos mesmo tratamento de pais ou mães que vivem em uma união heterossexual, não havendo, assim, distinção no que concerne à maternidade ou paternidade pelo tipo de união adotada pelos conviventes, posto que os casais homoafetivos, assim como os heterossexuais, desfrutarão de uma licença concedida indistintamente e pautada no critério do afeto que deve vincular pais ou mães aos filhos, tornando aqueles responsáveis conjuntamente e em patamar de igualdade pelos ônus relativos à formação da criança.

\section{CONSIDERAÇÕES FINAIS}

A mulher, no decorrer da história, deixou de ser apenas "dona do lar" e responsável pela criação de seus filhos, para participar ativamente do sustento da família, o que ocorreu com o aumento progressivo da sua participação no mercado de trabalho. Contudo, para alcançar tamanhas conquistas foi preciso que acontecessem mudanças tanto na sociedade quanto na rotina da mulher.

Existe a necessidade de modificar o pensamento de que as responsabilidades familiares são exclusivamente ou essencialmente femininas, o que faz com que as mulheres, em média, dediquem menos tempo ao trabalho fora do lar, o que, muitas vezes impõe o labor em tempo parcial, informal e precário. O trabalho das mulheres, diferente do que acontece 
com os homens, não depende apenas da demanda no mercado ou da sua capacidade para atendê-la, mas decorre também de uma articulação complexa de características pessoais e familiares.

A CF/1988 representou o grande marco jurídico para uma mudança significativa na concepção da igualdade entre homens e mulheres. A proteção à maternidade foi uma forma encontrada para compatibilizar o ciclo vital humano à ordem econômico-social, sendo uma ferramenta essencial para proporcionar à mulher trabalhadora o equilíbrio necessário para conciliar sua vida profissional com a familiar.

Afirmar a importância da licença maternidade e a necessidade de recuperação da mulher após o parto, bem como a indispensabilidade da amamentação, não significa dizer que a paternidade não tenha importância ou tenha relevância secundária nas relações familiares.

O menor tempo de licença paternidade afasta a possibilidade e o estímulo a uma maior responsabilização dos pais pelos encargos familiares, reforçando a discriminação contra a mulher e a manutenção de uma sociedade patriarcal. De igual modo, impede aos homens de estabelecer os primeiros vínculos de afeto com o seu filho, de forma integral.

Vale ressaltar que a legislação brasileira ainda não aborda as diversas situações que se fazem presentes atualmente na nossa sociedade, principalmente no que se refere à mudança dos conceitos de família, que, além da forma tradicional, hoje, englobam unidades monoparentais, assim como as homoafetivas, sendo necessário recorrer a processos administrativos e judiciais na tentativa de garantir o exercício dos direitos relativos às licenças analisadas.

Com base nesse estudo podemos concluir que a proteção à maternidade constitui um direito de extrema importância às gestantes, crianças adotadas ou biológicas e à sociedade como um todo, haja vista os seus diversos aspectos sociais de inserção da mulher no mercado de trabalho. Todavia, a dualidade, concebida pelo direito brasileiro e que se pauta na licença maternidade e paternidade, com prazos diferenciados, não concretiza o princípio constitucional da igualdade, na medida em que cria uma discriminação entre homens e mulheres no que atine às responsabilidades familiares com a criação dos filhos.

Além disso, a utilização isolada de uma ou de outra modalidade de licença para os pais ou mães que convivem em regime de união homoafetiva também afronta o citado princípio constitucional. No caso de união homoafetiva de pessoas do sexo feminino, apenas uma das mães, no caso de concepção biológica, desfrutará da licença, que será concedida à 
mãe responsável pela concepção, ficando a outra privada do exercício de tal direito. Na hipótese de união homoafetiva, de pessoas do sexo masculino, embora ambos os pais possam gozar do direito à licença paternidade, o tempo de convivência com o filho é bem menor do que aquele concedido à mulher.

Por essa razão, opinamos que a fórmula jurídica adequada e capaz de promover a real inserção da mulher no mercado de trabalho em condições de igualdade com o homem, como também de atender às novas formas sociais de família, é a licença parental cuja fixação não leva em conta o sexo do responsável pela criança, mas a necessidade de criação de vínculos entre os pais com relação à formação psíquica, física e social do filho, ademais de favorecer a distribuição equitativa de responsabilidades familiares entre os seus integrantes, viabilizando a ruptura do padrão patriarcal de família.

\section{REFERÊNCIAS}

BANDEIRA, Lourdes \& ALMEIDA, Tânia Mara Campos de. A violência contra as mulheres: um problema coletivo e atual. Disponível em: $<$ https://encontroprogramadeprotecao.files.wordpress.com/2012/02/a-violc3aancia-contra-asmulheres.pdf>. Acesso em: 09 de maio de 2017.

BARROS, Alice Monteiro de. A mulher e o direito do trabalho. São Paulo, LTr, 1995.

Curso de Direito do Trabalho. $4^{\mathrm{a}}$ ed. São Paulo, LTr, 2009.

BRASIL, Consolidação das Leis do Trabalho (1943). Decreto-Lei $\mathbf{n}^{0} \mathbf{5 . 4 5 2}$, de $\mathbf{1}^{\circ}$ de maio de 1943. Disponível em: <http://www.planalto.gov.br/ccivil_03/decretolei/Del5452compilado.htm>. Acesso em: 04 de fevereiro de 2017

BRASIL, Constituição (1988). Constituição da República Federativa do Brasil. Brasília: Senado Federal, 1988. Disponível em:

<http://www.planalto.gov.br/ccivil_03/constituicao/constituicaocompilado.htm>. Acesso em: 04 de fevereiro de 2017

BRASIL. Lei $\mathrm{n}^{\circ}$ 6.136, de 07 de novembro de 1974. Disponível em: <http://www.planalto.gov.br/ccivil_03/leis/1970-1979/L6136.htm>. Acessado em 01 de fevereiro de 2017. 
BRASIL. Lei $\mathbf{n}^{\mathbf{0}}$ 11.770, de 09 de setembro de 2008. Disponível em: <http://www.planalto.gov.br/ccivil_03/_ato2007-2010/2008/lei/111770.htm>. Acesso em: 01 de fevereiro de 2017.

BRASIL. Lei $\mathrm{n}^{\mathbf{0}} \mathbf{1 0 . 4 2 1}$, de 15 de abril de 2002. Disponível em: <www.planalto.gov.br/CCivil_03/leis/2002/L10421.htm>. Acesso em: 01 de fevereiro de 2017.

BRASIL. Lei $\mathbf{n}^{\mathbf{0}}$ 12.873, de 24 de outubro de 2013. Disponível em: <http://www.planalto.gov.br/ccivil_03/_ato2011-2014/2013/Lei/L12873.htm>. Acesso em: 01 de fevereiro de 2017.

BRASIL. Lei no 13.257, de 08 de março de 2016. Disponível em: <http://www.planalto.gov.br/ccivil_03/_ato2015-2018/2016/lei/L13257.htm>. Acesso em: 01 de fevereiro de 2017.

CALIL, Lea Elisa Silingowschi. Direito do trabalho da Mulher: a questão da igualdade jurídica ante a desigualdade fática. São Paulo: LTr, 2007.

DELGADO, Mauricio Godinho. Curso de Direito do Trabalho. São Paulo: LTr, 2010.

FARAH, Marta Ferreira Santos. Gênero e políticas públicas. Revista de Estudos Feministas. V.12, Núm. 1, jan-abr/2004. Florianópolis. Disponível em: <https://periodicos.ufsc.br/index.php/ref/article/view/S0104-026X2004000100004/7943>. Acesso em: 09 de maio de 2017.

HORVATH JÚNIOR, Miguel. Revisitando o salário maternidade à luz das recentes alterações. Disponível em: <http://www.ambito-

juridico.com.br/site/index.php?n_link=revista_artigos_leitura\&artigo_id=7907>. Acesso em: 09 maio 2017.

MANDALOZZO, Silvana. A maternidade no direito do trabalho. Curitiba: Juruá, 1996. MELLO, Celso Antônio Bandeira de. O conteúdo jurídico do princípio da igualdade. $18^{\mathrm{a}}$ Ed. São Paulo, Malheiros, 2011.

MEULDERS, Danièle et al. Trabalho e maternidade na Europa: condições de trabalho e políticas públicas. Disponível em: 
<http://www.scielo.br/scielo.php?script=sci_arttext\&pid=S0100-15742007000300006>. Acesso em: 09 de maio de 2017.

NASCIMENTO, Sônia A. C. Mascaro. Trabalho da Mulher: das proibições para o direito promocional. São Paulo: LTr, 1996.

OIT. Maternity Protection Resource Package. From Aspiration to Reality for All. Part. 1: Maternity Protection at Work: The Basics. 2012. Disponível em:

$<$ http://mprp.itcilo.org/allegati/en/m1.pdf>. Acesso em: 06 de fevereiro de 2017.

OIT. Convenção no 03. Convenção relativa ao Emprego das Mulheres antes e depois do parto (Proteção à Maternidade).1919. Disponível em:

$<$ http://www.oitbrasil.org.br/content/conven\%C3\%A7\%C3\%A3o-relativa-ao-emprego-dasmulheres-antes-e-depois-do-parto-prote\%C3\%A7\%C3\%A3o-\%C3\%A0-maternidade>.

Acesso em: 11 de maio de 2017.

OIT. Convenção no 103. Amparo à maternidade. 1952. Disponível em: <http://www.oitbrasil.org.br/node/524>. Acesso em: 11 mai 2017.

OIT. Convenção $\mathbf{n}^{\mathbf{0}}$ 156. Convenção sobre a igualdade de oportunidades e de tratamento para trabalhadores e trabalhadoras com responsabilidades familiares. 1981. Disponível em:

<http://www.oitbrasil.org.br/node/228>. Acesso em: 11 de maio de 2017.

OIT. Recomendação $\mathbf{n}^{\mathbf{0}}$ 165. Estabelece princípios e diretrizes para a aplicação da Convenção no 156. Disponível em: <http://www.oitbrasil.org.br/node/228>. Acesso em: 11 de maio de 2017.

TEIXEIRA, Daniel Viana. Desigualdade de gênero: sobre garantias e responsabilidades sociais de homens e mulheres. São Paulo, Revista Direito GV: 2010.

VIEGAS E SILVA, Roberta. Maternidade e mercado de trabalho: avanços possíveis. Disponível em: <https://www12.senado.leg.br/publicacoes/estudos-legislativos/tipos-deestudos/boletins-legislativos/bol42>. Acesso em: 09 de maio de 2017. 